\title{
A CONSTRUÇÁO DE UMA POLÍTICA DE JUVENTUDE COM OS JOVENS: POSSIBILIDADES E LIMITES DE UMA EXPERIÊNCIA CONCRETA
}

\author{
THE CONSTRUCTION OF A YOUTH POLICY WITH YOUNG PEOPLE: \\ POSSIBILITIES AND LIMITS OF A CONCRETE EXPERIENCE
}

\begin{abstract}
Rosemary Roggero Doutora em Educação: História, Política, Sociedade pela Pontifícia Universidade Católica de São Paulo. Docente do Programa de Mestrado e Doutorado em Educação e do Mestrado em Gestão e Práticas Educacionais da Universidade Nove de Julho, São Paulo, SP - Brasil ORCID: http://orcid.org/0000-0003-3084-4979 roseroggero@uol.com.br

Lee Oswald Siqueira Mestre em Educação pela Universidade Nove de Julho. São Paulo, SP - Brasil ORCID: http://orcid.org/0000-0002-2767-3614 lee.siqueira@outlook.com
\end{abstract}

Resumo: Este artigo é o recorte de uma pesquisa empírica sobre participação política da juventude, mas também é o relato de experiência de construção de uma política de juventude, junto aos jovens de um município da grande Sáo Paulo, nos anos de 2013 e 2014. A questão da pesquisa foi: até que ponto seria possível construir uma política pública com o envolvimento e a participação direta do público-alvo? O objetivo foi analisar as relaçôes que se estabelecem na construção de uma política pública com a participação direta dos jovens. O método é compatível com a pesquisa-ação interventiva, que implicou no desenvolvimento de uma cartografia da juventude na cidade e utilizou os procedimentos da indagação valorativa para sensibilizar, articular e mobilizar mais de 4 mil jovens com idade entre 15 e 29 anos, em 92 ciclos de diálogo, para refletir sobre suas potencialidades e levantar prioridades na construção de políticas específicas, tendo como pano de fundo a realização de uma pedagogia social. No processo, destacaramse lideranças que apresentaram ao poder público uma Carta da Juventude da cidade, chegou-se ao Projeto Lei para criaçáo do Conselho Municipal de Juventude e a um plano de ação para implementação do Estatuto da Juventude, no município.

Palavras-chave: Indagação Valorativa. Juventude. Políticas Públicas.

Aвstract: This paper is a review of an empirical research on youth political participation, but it is also the report of experience of building a youth policy, together with the youths of a municipality of. In the years of 2013 and 2014. The question of the research was: o what extent it would be possible to construct a public policy with the involvement and 
the direct participation of the target public? The objective was to analyze the relations that are established in the construction of a public policy with the direct participation of the young people. The method is compatible with the research intervention, which involved the development of a map of youth in the city and used the procedures of the valuation to sensitize, articulate and mobilize more than 4 thousand young people aged 15 to 29 years in 92 cycles of dialogue, to reflect on their potentialities and raise priorities in the construction of specific policies, having as background the realization of a social pedagogy. In the process, leaders who presented to the public power a Youth Charter of the city, arrived at the Project Law for the creation of the Municipal Youth Council and a plan of action for the implementation of the Youth Statute, in the municipality.

Keywords: Valuative Inquiry. Youth. Public Policies.

\section{Introdução}

De acordo com Caliman (2009, pp. 889-890):

A Pedagogia Social é uma ciência; ciência prática; ciência normativa; ciência descritiva; ciência que produz tecnologia educacional; ciência orientada para indivíduos e grupos; numa relaçáo de cuidado e ajuda; como promotora nas pessoas da capacidade de administrar seus riscos e emancipar sujeitos historicamente oprimidos; através de programas e instituiçôes socioeducativas.

É nessa perspectiva que inúmeras propostas, constituídas no contexto de um projeto social de inclusão, têm sido levadas a cabo, nas últimas décadas, predominantemente por organizações não governamentais. No entanto, nesse contexto, também tem se buscado a ampliação da participação social para uma cidadania mais ativa, em que o cidadão possa reconhecer-se como sujeito de direitos, mas também pautado por uma dinâmica de colaboração e participação, por meio de conselhos de cidadania, nas várias esferas da vida pública.

Gohn (2006) afirma que a pedagogia social é um campo em construção e avalia a relevância de se observar como se dá a participação da sociedade civil organizada em estruturas colegiadas de interação entre o poder público o território que gere. Nesse processo, buscam-se as aprendizagens que podem acontecer nas interaçôes geradas pelo processo participativo. É nesse sentido que se insere a experiência aqui descrita, numa 
perspectiva que toma a pedagogia social como uma ciência prática da educação, pautada numa compreensão ampliada da socialização do sujeito para uma prática social qualificada e emancipada.

$\mathrm{O}$ aspecto deste texto relativo ao relato de experiência pauta-se na descrição da aplicação da metodologia e dos processos decorrentes da participação dos jovens de um município de médio porte, demonstrando que é possível buscar e alcançar essa participaçáo qualificada e emancipada na construção de políticas públicas legítimas e autênticas.

Historicamente, o município já desenvolvia açóes direcionadas para os munícipes com idade entre 15 e 29 anos, sob responsabilidade de várias secretarias. Contudo, no contexto das políticas públicas de inclusão social, no Brasil, a administração municipal entendeu ser necessário o desenvolvimento de açóes que estabelecessem conexóes entre as políticas públicas existentes e os jovens beneficiários dos programas de garantia de direitos, ainda que não só estes, mas toda a juventude da cidade.

O Plano de Governo 2013-2016 apresentava a proposta de constituição de uma política específica e direcionada e, para tanto propunha a criação de um Conselho e uma Coordenadoria de Juventude que articulassem as políticas municipais existentes e, eventualmente, novas políticas, constituindo um locus de diálogo e aperfeiçoamento de açóes ligadas a esse segmento.

Foi nesse âmbito que se desenvolveu o projeto Juventude Mogiana, sob a coordenação da secretaria de Educação, no âmbito da educação nãoformal, que assumiu o papel de articuladora entre as demais secretarias municipais e as lideranças jovens.

Mas o artigo não se esgota no relato de experiência. A análise crítica do processo, em relação ao público atingido e às questôes que o envolvem será apresentada em seguida.

\section{Primeiros passos}

Nos primeiros meses de 2013, um grupo de 21 jovens, uma comissáo de apoio da secretaria de Educaçáo e dois vereadores realizaram um primeiro encontro, em que foram apresentados os princípios, os objetivos, as metas e uma metodologia de trabalho voltados à sensibilização, 
articulação e mobilização de jovens em torno da criação de uma política de juventude.

A proposta aprovada pelo grupo apresentou como objetivo: sensibilizar, articular e mobilizar o maior número possível de jovens com idade entre 15 e 29 anos, para refletir e dialogar sobre suas potencialidades e prioridades em relação a políticas públicas. A juventude da cidade foi convidada a pensar sobre sua condição cidadã e desenvolver um plano de participaçáo, por meio de jovens lideranças, que usaram seus canais de comunicação com seus grupos e suas práticas específicas, para possibilitar uma aproximação entre esses vários grupos e o poder público.

Com o objetivo de alcançar o maior número de bairros na mobilização, os organizadores definiram a utilização da divisão administrativa do município como base para a distribuição de responsabilidades. O território foi compreendido a partir da composição definida em oito distritos e o centro: Braz Cubas, Biritiba Ussú, Bairros da Divisa, Cézar de Souza, Jundiapeba, Sabaúna, Taiaçupeba, Quatinga, e distrito Sede. A técnica de pesquisa escolhida para dinamizar o processo foi a Indagação Valorativa (COOPRRIDER, 1999), que apresenta uma forma peculiar e dinâmica de mapeamento de interesses e potencialidades, bem como a valorização dos ativos individuais e coletivos da comunidade, conforme será descrito adiante.

No que tange o processo de sensibilização, o grupo utilizou a descentralização por distrito e, simultaneamente, por bairros, mapeando as lideranças e articulando-as para a participação dos Ciclos de Diálogo; o segundo passo, ainda neste primeiro momento, foi mobilizar os esforços para criar ambientes dinâmicos que garantissem aos jovens uma identificação com a proposta e o interesse em participar. Foram constituídas comissôes de apoio e de processos, que acompanharam de perto a criação dos planos de ação, formadas por representantes públicos e representantes das comunidades jovens, que foram preparados como sensibilizadores, mobilizadores e articuladores para se tornarem os responsáveis por integrar os grupos e possibilitar os ciclos de diálogos, condição indispensável para a produção democrática da participação. Toda essa dinâmica é descrita detalhadamente a seguir, tendo em vista as possibilidades de replicação da experiência; e, posteriormente, analisada em seus processos e resultados, no contexto. 


\section{O Plano de Trabalho}

O projeto foi dividido em quatro fases, em alguns casos executadas simultaneamente, porém cada fase com açóes claras desenvolvidas para alcançar os objetivos delineados.

1a Fase - Sensibilização - Construção, aprovação e apresentação da proposta. (Fev / Abril 2013).

- Em fevereiro de 2013, a secretaria de Educação, incumbida dessa ação pelo prefeito, criou a comissão para desenvolvimento do pré-projeto de mobilização, com o objetivo de oferecer uma contribuição para a construção da política de juventude na cidade.

- Em 26 de março de 2013, foi realizada uma reuniáo em que a comissão apresentou o projeto para a comissão de educação da Câmara Municipal e secretários de educação, cultura, saúde, desenvolvimento social, habitação, jurídico, verde e meio ambiente e esporte e lazer.

- Em 07 de abril de 2013, a comissáo promoveu o primeiro encontro de lideranças juvenis na câmara municipal com a presença de 23 representantes da sociedade civil e 7 do poder público, já engajados com propostas ligadas à juventude.

- Em 08 de abril de 2013, o projeto foi apresentado para os oito administradores regionais dos oito distritos oficiais do município e representantes do distrito sede.

2a Fase - Articulação - ampliação do número de jovens participantes e multiplicadores e execução dos Ciclos de Diálogo. (Mai /Ago. 2013). Ação 1- Mobilização de lideranças juvenis da cidade para constituição das comissóes.

Ação 2 - Constituição das comissões:

- Comissão de gestão de processos

A comissáo de gestão de processos foi formada por um grupo de 12 participantes, entre eles: secretários municipais, diretores de departamentos e administradores regionais da prefeitura, bem como lideranças jovens com grande capacidade de representação em seus bairros. A missão deste 
grupo era criar estratégias de atuação nos distritos, realizar e acompanhar as atividades.

- Comissão de articulação

A comissão de articulação foi composta por 23 jovens participantes ativos nos encontros, lideranças dos nove territórios, com a função de articular mobilizadores/multiplicadores em suas localidades de representação. Com base nessa representação, os participantes tinham como tarefa criar as condiçóes para a ampliação das açóes e realização dos ciclos de diálogo, em locais específicos.

- Comissão de mobilização

Em cada bairro foi criada a comissão mobilizadora, cuja tarefa era convidar outros jovens para participar das discussôes locais. Esse grupo foi formado por representantes de grupos ou tribos, com legitimidade para falar em nome dos demais, no que tange à representação coletiva.

Nesse processo, foram realizadas 6 assembleias da comissão de gestão de processos, com seus 12 membros; 8 reuniôes da comissão de articulação com uma média de 23 participantes em cada encontro; 91 ciclos de diálogo que alcançaram 4072 jovens, de acordo com os registros organizados pela comissão de gestão de processos.

- Em 11 de abril, aconteceu a primeira reunião ampliada de lideranças com a presença de 41 jovens representando os oito distritos e o Distrito Sede. O encontro aconteceu no CIARTE - Companhia de Arte, equipamento da Secretaria de Cultura do Município, para a formação sobre a metodologia da indagação valorativa e para discutir como poderiam ser tematizados os ciclos de diálogo.

- No dia 16 de abril, a comissáo de gestáo de processos decidiu assumir os Objetivos de Desenvolvimento do Milênio (ODM), programa internacional para melhoria das metas estabelecidas pela ONU para o desenvolvimento humano no mundo, como forma de tematizar os Ciclos de Diálogo.

- No dia 18 de abril, foi instituída a comissão de sensibilização (estratégica) do projeto que contou, inicialmente, com representantes das Secretarias de Educação, Cultura e Verde e Meio Ambiente, 
representantes da Câmara dos Vereadores e oito jovens lideranças da cidade.

- Em 25 de abril, esse grupo passou a contar com a "TV Nova Comunitária" e com o portal "O som da quebrada" para efetivação da comunicação.

- Em 30 de abril, aconteceu o segundo encontro de lideranças, com 83 jovens e a instituição da comissão de articulação municipal, contando com 18 lideranças.

- Em 06 de maio, foi constituída a subcomissão de comunicação do que se convencionou com os jovens denominar Movimento Juventude Mogiana, contando com 11 jovens, quando foi construído o plano de comunicação.

Importante salientar que a juventude foi unânime em não querer a participação da imprensa tradicional da regiáo. Não queriam o processo mediatizado. Por um lado, a organização gostou da proposta, mas não era possível saber se a imprensa respeitaria isso. Respeitou.

Também é importante ressaltar que os jovens definiram que seria importante manter uma independência em relação ao poder público e criarem uma identidade própria. Vale lembrar que esse processo todo aconteceu no calor das manifestaçóes populares de 2013.

- Em 08 de maio, a comissão de mobilização apresentou o projeto para a diretoria regional de ensino (dirigente regional e 32 supervisores) para acesso aos jovens estudantes do Ensino Médio.

- Em 17 de maio, representantes do poder público visitaram o Bispo da regiáo, para apresentar o projeto e conquistar o apoio da igreja católica, o que aconteceu imediatamente.

- Em 20 de maio, o projeto foi apresentado pelo poder público para uma comissão de 19 pastores de igrejas evangélicas, com objetivo de consolidar parcerias para a mobilizaçáo de jovens evangélicos. Também houve adesão imediata das lideranças presentes.

$3^{\text {a }}$ Fase - Mobilizaçáo da juventude, processo de ampliaçáo da proposta para o nível municipal e divulgação do resultado das audiências jovens. 
Ação 1 - Execução dos Ciclos de Diálogos:

Realização de Ciclos de Diálogo para construção do portfólio de questóes que norteariam as discussóes na etapa das audiências posteriores: para executar os diálogos em cada ciclo, definiu-se como estratégia partir dos temas propostos pelos Objetivos de Desenvolvimento do Milênio (ODM). Os objetivos se tornaram geradores de pesquisas dos jovens e potencializadores de reflexôes nos grupos e, para tanto, foram ajustados à linguagem dos jovens participantes, de acordo com os seguintes temas: Oportunidade de trabalho para a Juventude; Educação profissional como como alternativa; Respeito à diversidade; Redução da violência e mortalidade juvenil; Saúde individual e coletiva dos jovens; Atenção à questão da drogadição; Esporte, cultura e lazer, como propostas; Direito à informação e incentivo à participação.

Os temas oficiais dos ODM foram definidos pela Organização das Naçôes Unidas (ONU) para dar resposta aos grandes problemas da humanidade, questionados em Conferências Internacionais. Estiveram em vigor até o ano de 2015 e os temas adaptados às realidades dos jovens foram definidos pela comissão de gestão de processos e comissão de articulação, a partir dos quais foram geradas as perguntas positivas incondicionais (procedimento metodológico indicado pela Indagação Valorativa como forma de aproximação dos anseios do público alvo).

A participação da juventude avançou por meio da mobilização de todos os setores e segmentos, buscando respeitar as particularidades regionais, sobretudo entre as áreas urbanas e rurais.

Construir o diálogo entre as potencialidades locais e os interesses juvenis, pareceu ser uma forma estratégica para alcançar a clareza necessária das prioridades que a juventude tinha, em relação à cidade. Os bons resultados da mobilização e o processo de diálogo pareciam alimentar os sonhos desses jovens. Eles foram assumindo a responsabilidade por promover ambientes de integração e dinamismo, que favoreciam a realização dos Ciclos de Diálogo, alcançando cada vez mais grupos.

Ação 2- Execução dos ciclos de diálogo e composição das cartas de juventude distritais.

Os ciclos de diálogo foram realizados em bairros dos distritos, conforme segue: Braz Cubas, 18 ciclos e 620 jovens; Biritiba Ussu, 09 ciclos 
e 417 jovens; César de Souza, 13 ciclos e 412 jovens; Jundiapeba, 8 ciclos e 302 jovens; Quatinga, 5 ciclos e 71 jovens; Taiaçupeba, 8 ciclos e 111 jovens; Sabaúna, 6 ciclos e 317 jovens; Sede (bairros da região central), 21 ciclos e 1730 jovens.

É importante salientar que a quantidade de ciclos de diálogo por distrito esteve relacionada à extensão territorial, região urbana e rural, bem como ao índice populacional, variedade de tribos jovens e dinâmicas do processo dialogal. Os territórios possuem, naturalmente, suas especificidades, o que garantiu a participação de lideranças ativas, que tinham credibilidade diante da comunidade jovem, e a riqueza dos resultados alcançados. Quando essas lideranças assumiam integrar sua força ao processo de sensibilização e articulação geravam mobilização muito rapidamente e, consequentemente, solicitavam um maior número de ciclos de diálogo.

A vertente positiva da participação gera um comprometimento que é multiplicado na comunidade. A utilização da indagação valorativa e a temática dos ODM para os diálogos, ao invés de resultar num muro de lamentaçôes, criou um cenário de descobertas que possibilitou aos jovens o direito de expressão e a oportunidade de participação efetiva e organizada.

Todas as 25 escolas de Ensino Médio público da cidade abrigaram ciclos de diálogo, a partir da indicaçáo e disponibilidade dos jovens da comissão local de mobilização. Os próprios jovens entraram em contato com cada direção de escola e fizeram a sensibilização. Em seguida, a comissão de articulaçáo ampliou o contato e desenvolveu, conjuntamente, um plano de execução dos ciclos de diálogos nessas escolas.

Também foram executados Ciclos de Diálogo em 12 Organizações Sociais: A Associação Nova Esperança e a Mãe Maria Medianeira, da Vila Nova União; a Associação Mogiana, do São João; a Legião da Boa Vontade, da Vila Moraes; a Demolay (Maçonaria Masculina Jovem) e as Filhas de Jó (Maçonaria Feminina Jovem), da Vila Oliveira; o Rotaract e o Lyons Club, do Socorro; o Pro Jovem Trabalhador Raízes, a Academia Social Alfa e a Comunidade de Reabilitação, de Judiapeba; e, ainda, o Grupo Baraúna, de Braz Cubas.

As organizações sociais apresentaram maior facilidade de aproximaçáo com o tipo de ação proposta pelo projeto. Para seus gestores, existe uma identificação natural com o trabalho de sensibilizar e mobilizar comunidades em prol de direitos e do bem comum. 
Foram executados, ainda, 26 ciclos de diálogo em igrejas e templos da cidade.

As instituiçóes religiosas, desde o início, foram percebidas como grande potencial para o processo de sensibilização e mobilização dos jovens. Presentes em todas as comissóes, as jovens lideranças confessionais atuaram no mapeamento dos anseios de seus grupos.

Os Ciclos de Diálogo são eventos que valorizam o potencial dos atores e abrem espaço para construção de plataformas de oportunidades a partir de um desenho prático:

$1^{a}$ Etapa: Descoberta - A primeira etapa do processo, usando a indagação valorativa, tratou das atividades em torno da descoberta, entendimento e reconhecimento do que existe de positivo, levantando ou validando dos ativos dos territórios.

2a Etapa: Sonho - Nessa etapa, foram reunidas as informações do grupo, ou dos grupos, sistematizadas de forma que pudessem definir claramente o "sonho" dos participantes para aquele território.

$3^{a}$ Etapa: Planejamento - A terceira etapa foi composta pelo levantamento de proposiçóes ou desafios dos grupos, que se apresentou no sentido de articular "o que poderia ser", efetivamente.

4a Etapa: Destino - Esta última etapa dos ciclos foi momento de produzir consensos e finalizar o desenho que resultou de todas as etapas. Elaborou-se um documento propositivo de açóes para o tema central das políticas públicas para jovens na cidade, em que foi possível apresentar a visão dos jovens mogianos sobre temas essenciais no cotidiano, na cidade.

No contexto de participação e engajamento social, que ganhou as ruas em junho de 2013, os jovens entenderam que não poderiam deixar de dar sua contribuição no calor das manifestações que eclodiam naquele momento, porém em reuniáo no dia 08 de junho, entenderam que manifestar-se da forma como se propunham os grupos pelo Brasil náo era a estratégia que queriam adotar, preferiram se identificar como movimento, mas com uma forma própria de se manifestar e reivindicar. Assim, 
passaram a se reconhecer e se apresentar como Movimento da Juventude Mogiana e mantiveram o foco na luta pela criação de uma política pública para a juventude da cidade. Criaram páginas em redes sociais e procuraram ir construindo sua identidade.

A forma de atuação se manteve por meio do diálogo e da busca de uma relação sadia entre os membros individuais, as comissóes oficiais e os jovens reunidos nos ciclos de diálogo, nos bairros da cidade. Este foi um dos inúmeros momentos reveladores do processo. Os organizadores puderam perceber a riqueza da metodologia utilizada e da tematizaçáo, sempre respeitando os princípios da construçáo coletiva e de acolhimento à diversidade de posicionamentos.

Para exemplificar: um grupo de jovens de Jundiapeba havia marcado ciclo de diálogo para o dia 21 de junho de 2013, na Escola Estadual Vânia Cassará, mesmo dia e horário da manifestação marcada pelo Movimento Passe-Livre, que mobilizava o país. Ao serem questionados sobre a possibilidade de remarcar o ciclo, os jovens do bairro definiram por manter a programação, considerando que estar reunidos e discutindo suas prioridades para a juventude do bairro, seria táo importante quanto participar da manifestação no centro da cidade.

Ação 3 - Execução das Audiências Jovens em cinco distritos da cidade.

As audiências jovens foram realizadas em 15 de agosto, em César de Souza; em 22 de agosto, em Braz Cubas; em 29 de agosto, em Biritiba Ussu; em 5 de setembro, na região central; em 12 de setembro, em Jundiapeba.

As audiências jovens foram instrumentos propostos pelos jovens, como forma de ampliar o diálogo entre o poder público e eles, com o intuito de apresentar suas prioridades e buscar alternativas para a solução de problemas de público, por meio de apresentaçóes distritais. Também serviram como instrumento para a coleta de mais informaçóes (depoimentos, opinióes, diagnóstico de potenciais) e esclarecimento de possíveis dúvidas sobre as peculiaridades de cada distrito. Nesse evento, os jovens apresentaram as cartas distritais da juventude, documentando o pensamento da juventude local.

Esse diálogo democrático, promovido entre os atores sociais nas audiências jovens distritais, possibilitou maior aproximação com representantes do executivo e do legislativo. Foi possível, por parte dos jovens, expressar suas angústias e seus conflitos, mas também apresentar sua visão 
sobre a região em que vivem com seus potenciais e indicar possibilidades para minimizar os problemas e conflitos locais.

Ação 4 - Encontros de planejamento para execução do congresso de juventude. (04 reunióes 02/09 - 09/09 - 16/09 - 19/09)

Ação 5 - Execução do I Congresso da Juventude Mogiana organizado pelo Movimento Juventude Mogiana. (20 e 21 de setembro no Centro de Formação Pedagógica da cidade. (CEMFORPE)

O congresso foi realizado em dois dias consecutivos 20 e 21 de setembro de 2013 e dividido em três partes. A primeira parte compreendeu o Festival de Tribos Juvenis, na Praça Botyra Camorim Gatti. Localizada no Centro Cívico, é um espaço destinado aos jovens da cidade, mas que recebe muitas críticas por ser utilizado por usuários de drogas e outras atividades ilícitas. A proposta da comissão de mobilização de realizar ali o Festival de Tribos Juvenis foi a ressignificação desse espaço, oferecendo aos jovens outras possibilidades de ocupá-lo. O evento contou com dois palcos musicais com estilos diversos: samba, funk, eletrônica, forró, rap e outros, e um trio elétrico que trouxe o estilo gospel. $\mathrm{O}$ evento também contou com intervençôes teatrais, circenses e campeonato de skate. A proposta foi unir diversas tribos de jovens da cidade e celebrar a vida e as possibilidades que nascem com esse novo espaço de participação. Foi um belíssimo evento, em que estiveram presentes cerca de 1.300 jovens, mas também famílias com crianças e idosos. A guarda municipal avaliou muito positivamente o evento, mencionando não ter havido nenhum problema, ao longo de sua realização.

- Na segunda parte, deu-se o participatório, espaço de diálogo entre as lideranças, do qual participaram cerca de 300 jovens, com o objetivo de sistematizar as cartas distritais e compor uma carta municipal que expressasse o pensamento da juventude mogiana como um todo.

- A terceira parte foi o encerramento do congresso com um evento que contou com apresentaçóes artísticas dos jovens e espaço de valorização dos diálogos. Foi, portanto, um momento festivo, com participação de cerca de 500 jovens representantes dos nove distritos da cidade. 
Ação 6 - Entrega da Carta da Juventude Mogiana ao Prefeito. (15/ out/2013)

Ocorreu em 15 de outubro de 2013, o evento de entrega oficial da Carta da Juventude Mogiana ao Chefe do Executivo, por 15 jovens lideranças. Foram recebidos, ouvidos e puderam apresentar suas expectativas como uma síntese do olhar da juventude da cidade sobre ela mesma. O Prefeito solicitou ao grupo apresentasse, entáo, por meio de minuta, a proposta de constituição do Conselho Municipal de Juventude.

Ação 7 - Constituição da comissão de acompanhamento dos encaminhamentos.

Ação 8 - Acompanhamento da formulação do Projeto Lei para constituição do Conselho Municipal de Juventude.

A comissão que representava o movimento Juventude Mogiana no ato de entrega da carta iniciou um diálogo para definir se o Conselho seria resultado do processo e, portanto, o fim do Movimento ou se continuariam com as açôes do Movimento em paralelo às açôes do Conselho.

No encontro, o prefeito indicou que esses jovens deveriam participar de uma formação que os ajudasse a compreender os processos políticos, na atualidade, o que foi prontamente aceito pelo grupo, que solicitou o desenvolvimento do mesmo pelo poder público. O curso de Fundamentos das Políticas de Juventude foi realizado ao longo do ano de 2014, como uma das primeiras ações da Escola de Governo, implantada no mesmo ano, no município.

\section{Juventude e comunidade em foco: uma perspectiva cartográfica}

Nosso objeto de estudo foi a juventude que residia, aparentemente inerte e adormecida, nas entranhas das comunidades, para compreender o universo em que se estabelecem as relaçóes na cidade, ou seja, de que co- 
munidade estamos tratando, qual o olhar dessa juventude sobre si mesma, a cidade e o território onde vive?

Para o jovem mogiano, ser interpelado em relação ao seu olhar para a cidade esbarra em um cenário singular. A cidade, conforme a percebemos, apresenta formas distintas no seu espaço urbano e expóe um fosso que divide os grupos, entre elites que convivem em bairros específicos e um contingente de outros moradores em territórios menos abastados; vale salientar que esse olhar tende a mudar dependendo do território e da perspectiva do observador. Assim, não se trata apenas da velha divisão de classes, mas de outras categorias que vão se entrelaçando, se revelando e se contemplando na paisagem.

Foram vários os desafios encontrados pelos grupos de jovens na construção desse olhar sobre sua comunidade e a cidade. Dar-se conta de que fazem parte de um grupo maior de interesses significou e exigiu reflexão para uma reordenação das prioridades que, nos primeiros ciclos de diálogo, beiravam reivindicaçôes quase vazias. Nesse cenário, foi possível incitar os jovens participantes na perspectiva do levantamento de informaçóes positivas sobre suas localidades, gerando um processo de descoberta do novo em meio ao supostamente conhecido, que possibilitasse sonhar e pensar o percurso para o resultado.

A juventude mogiana aparece quase sempre associada a dimensóes e problemas típicos da sua condição e de todas as expectativas que lhe são apresentadas, tanto no país quanto no mundo, que são consideradas as peculiaridades de cada local.

Percebemos que as questóes muito presentes são: as do mundo do trabalho, as das desigualdades entre homens e mulheres, e as das situaçóes de vulnerabilidade. Estas estão com frequência associadas à má qualidade na educação, às situações de violência e à incoerência na distribuição de oportunidades; enfim, as preocupaçôes juvenis são consonantes com as dinâmicas da sociedade como um todo, em seus avanços e conflitos.

A seguir, dentro das inúmeras possibilidades interpretativas que poderíamos fazer das cartas, tanto as distritais quanto a municipal, selecionamos as prioridades para essas juventudes em relaçáo à comunidade e às necessárias políticas em prol dos jovens. 


\section{Formação/qualificação/mercado de trabalho: interseçóes necessárias}

A partir dos resultados obtidos nos ciclos de diálogo, foi possível perceber grande preocupação dos jovens na relação entre sobrevivência e trabalho. Quando reescreveram o objetivo 1 dos ODM, "acabar com a fome e a miséria”, e o relacionaram com a necessária educação e formação para o trabalho, esses jovens poderiam estar relacionando educação e consumo, pois não há possibilidade de consumir sem acesso ao dinheiro. Como acessar o dinheiro sem trabalho e como fazê-lo sem uma formação adequada?

O município de Mogi das Cruzes, segundo dados do Seade (SÃO PAULO, 2013), possui aproximadamente $40 \%$ da populaçáo jovem de 18 a 24 anos sem ensino médio completo, isso para uma populaçáo de aproximadamente 50 mil jovens nessa faixa etária. Os dados Seade também revelam que aproximadamente $4 \%$ da população, o equivalente a 16 mil pessoas do município com mais de 15 anos, não tem escolarização, para uma população de aproximadamente 400 mil habitantes.

Para os jovens, não há como garantir uma sociedade sustentável se não houver uma preocupação com as pessoas, é preciso formar as crianças e os jovens para a compreensão e superação das condiçóes do mercado, mas é urgente que sejam vistos como seres em desenvolvimento e com o respeito devido aos limites e possibilidades dessas fases da vida.

Para Bauman (2013b), a juventude se defronta com a expectativa da mobilidade descendente. A geração anterior foi treinada para cultivar a esperança de que aquelas crianças, hoje jovens, seriam o futuro esperado e aguardado. Essa expectativa estava baseada e sustentada na ideia de que essa geração teria melhores condições de vida e formação. Esperava-se que a reprodução intergeracional do sucesso continuasse em alta, de forma a superar as realizaçóes de seus antecessores. Mas, durante o processo de escuta das experiências, sobretudo nos bairros da periferia e da zona rural, nem sempre parece táo simples o acesso sequer ao ensino médio ou a conclusão do fundamental, por exemplo.

Os jovens de Quatinga, bairros da divisa, Biritiba Ussu e Taiaçupeba nos indicaram certa preocupação, pois mesmo com a aparente facilidade de acesso à educação, esta não tem qualidade suficiente para que acreditem 
ser uma porta de saída que garanta condiçóes de acesso melhor ao mercado de trabalho ou ao sucesso imaginado.

Para Adorno (1986, p.70), "o interesse objetivo e a espontaneidade subjetiva separam-se, contudo; esta corre o risco de atrofiar-se sob a desproporcional superioridade das condiçóes dadas." Talvez essa forma de compreensão sirva para explicar o motivo pelo qual aquela grande parcela de jovens não tenha finalizado o ensino médio.

Encontramos nos ciclos de diálogo vários educadores jovens também preocupados com o discurso sobre a responsabilidade deles e a ineficiência do sistema escolar. Esses professores se sentem táo ineficientes quanto o sistema e, por mais que tentem, não conseguem encontrar uma fórmula mágica para solucionar os entraves da relação entre escola e vida, que inclui o mercado de trabalho. Bauman (2010b, p. 60), quando se refere aos desafios acima apresentados e a relação com a informação:

No passado, a educação assumia muitas formas e era capaz de adaptar-se às circunstâncias mutáveis, de definir novos objetivos e projetar novas estratégias. Mas, se me permitem a insistência, as mudanças presentes são diferentes das que se verificam no passado. Em nenhum dos momentos decisivos da história humana os educadores enfrentam um desafio comparável ao que apresenta esse ponto limite. Nunca antes deparamos com situação semelhante. A arte de viver num mundo hipersaturado de informaçôes ainda não foi aprendida. E o mesmo vale também para a arte ainda mais difícil de preparar os homens para esse tipo de vida.

A juventude de César de Souza indica claramente essa dissonância entre o papel da escola e os anseios da juventude objeto de suas realizaçôes: Em relação à educação profissional, o Distrito, apesar da proximidade com o centro da Cidade, não tem facilidade em conseguir acesso às escolas de formação técnica (ETEC e FATEC). Os jovens indicam uma atenção especial para a possibilidade de uma unidade escolar técnica na localidade, a ampliação do Sistema 'S' e unidades de formação de profissionalização na área de serviços. A juventude deseja acessar o mercado de trabalho, mas encontra grande dificuldade em sua formação e, portan- 
to, solicita a instalação de uma unidade do Centro de Apoio à Educação de Jovens e Adultos (Crescer) para dinamizar a formação local. (CARTA DISTRITAL DE CÉSAR DE SOUZA, 2013)

O Crescer é um projeto da prefeitura que une a qualificação profissional básica e a educação e objetiva estimular a elevação da escolaridade dos que não frequentaram ou não permaneceram na escola na idade própria, além de ofertar cursos de qualificação profissional básica a alunos matriculados na EJA e outros cidadáos mogianos.

Esses jovens em seus discursos apresentam descontentamento, por vezes profundo incomodo, ao elencar suas possibilidades de sucesso, na realidade atual. Para eles, a formação que lhes é oferecida não responde às expectativas, e parafraseando Bauman (2010b, p. 41): "a perspectiva de ser uma única coisa na vida inteira é repulsiva e apavorante."

Aqui, nos indagamos sobre outro ponto forte. No distrito de Braz Cubas, alguns jovens questionam a oferta de cursos sem ligação direta com o mercado, uma vez que diplomas ou certificados já não garantem perspectivas de sucesso no trabalho. Bauman (2010b, p. 65) diria que "trata-se, na verdade, de outro jogo, totalmente novo."

Esse jogo se estabelece quando da passagem do capitalismo liberal para o capitalismo de monopólios, que gera uma nova configuração do sistema capitalista, um novo jogo que Adorno (1986) denominará de capitalismo tardio. Essa configuração difunde uma cultura aparentemente interessada no indivíduo e na construção de uma sociedade democrática que tenderia a harmonizar as contradiçôes, mas, na verdade, alimenta a desigualdade e a exclusão.

Se muitos dos jovens que buscam o mercado de trabalho, na atualidade, mostram-se bem mais informados, já não aceitam tão facilmente as regras do jogo, também não conseguem questionar essas regras e, talvez, por essa razão, prefiram voltar das entrevistas de mãos vazias.

Centenas de jovens mogianos carecem de habilidades básicas de leitura, escrita e cálculo e nos apresentam, muitas vezes, um portfólio de atividades já realizadas no campo, porém com uma renda abaixo dos pisos salariais urbanos, em um contexto de trabalho cada vez mais limitado e pouco alinhado às novas tecnologias de agricultura sustentável. Esses jovens aparecem muito claramente definidos nos distritos de Quatinga, Biritiba Ussu e Taiaçupeba, onde suas vozes são raramente ouvidas, con- 
tudo eles querem fazer parte da estratégia de desenvolvimento dessas localidades:

Temos desejos, temos vontade de participar da vida pública do nosso município. Nós somos o maior ativo do nosso distrito! [...] O nosso distrito está cravado em meio a riquezas naturais, que se bem aproveitadas poderão nos garantir um futuro brilhante. Temos um cinturão verde, onde pode ser encontrado o melhor da agricultura (hortas, frutas, legumes e flores). Imaginem que grande parte dos nossos jovens sobrevive da agricultura, porém não temos qualificação necessária. Imaginem se tivéssemos uma escola técnica agrícola? [...] Talvez o que nos falte são projetos de qualificação profissional e incentivo para percebermos o quanto podemos!!! (CARTA DE BIRITIBA USSU, 2013)

Para eles, o fato de terem nascido nessas regióes ou nas condiçóes próprias a essa realidade significa ter menos chance de desenvolver suas habilidades, que lhes permitiriam empregos dignos e sair da marginalidade:

Mas, não temos só problemas. Não temos a intenção de apresentar um distrito obscurecido por dificuldades. Queremos mostrar o quanto somos fortes e podemos! [...] o maior ativo de nosso distrito são as pessoas, são os jovens que estấo em plena capacidade de produção. (CARTA DISTRITAL DE BIRITIBA USSU, 2013)

\section{A violência contra os jovens: efeito colateral de uma sociedade desigual}

O Mapa da Violência 2016 indica que o Brasil, com sua taxa de 27,4 homicídios por 100 mil habitantes, supera largamente os índices dos 12 países mais populosos do mundo. Só o México se aproxima: sua taxa foi de 22,1 . 
A violência, no olhar dos jovens mogianos, não acontece de maneira uniforme em todas as regióes, nem da mesma forma para os grupos etários, classes sociais e gêneros. Nas suas comunidades, a violência com resultado letal, atinge principalmente os homens. Quando se trata de violência doméstica, a vítima normalmente é a mulher jovem e a violência moral atinge principalmente negros e jovens homossexuais. Todos têm alguma história muito próxima para contar, quando não a própria.

$\mathrm{Na}$ compreensão dos jovens, a violência se dá a partir de três dimensôes específicas: falta de sentido para viver, falta de educação e falta de oportunidade na vida. Para os jovens, a cidade de Mogi das Cruzes apresenta uma constância na violência "por náo cuidar mais fortemente dos interesses dos mais jovens.” Para eles, a violência começa sempre em casa e alcança a escola como reprodutora de violência.

Mogi das Cruzes não possui publicados seus índices de violência, não aparece entre os 100 municípios mais violentos do país, de acordo com o mapa da violência nacional. Mas, ao se observar as condiçóes sociais do município e, a partir dos noticiários locais, pode-se perceber que a violência permeia o cotidiano, a mesma sensação que os jovens indicam nas suas cartas distritais, sobretudo nos bairros com alta densidade populacional, índices de vulnerabilidade e exclusão e alta incidência de desemprego.

Para os jovens, a ausência de espaços públicos de lazer, esporte e cultura, entre outras condiçóes, favorece a incidência de crimes e violência. A percepçáo de ausência do estado contribui para o sentimento de abandono e degradação, que colabora com o caos urbano das regióes periféricas e, consequentemente, gera um sentimento de insegurança nas comunidades. Existe um medo instalado na voz e na mudez dos mais jovens,

traduzidos pelos jovens de classe média como risco de ausência da família, não passar no vestibular, não poder viver os seus sonhos, os amores e a impossibilidade da completude da sua existência. Para os mais vulneráveis, os medos estão na falta de trabalho, oportunidades escassas e futuro incerto. Contudo, nessa fase da vida, parecem incitar novos projetos e desafios. Para Bauman (2010b, p.74), "os medos agora são difusos, eles se espalham. [...] é isso que faz com que os medos sejam terrivelmente fortes, e os seus efeitos sejam difíceis de amenizar. [...] os medos são muito diferentes, mas eles se alimentam uns dos outros." 
Os jovens entre 18 e 24 anos estão preocupado com a barbárie social instalada; seus medos se referem às drogas, à marginalidade a que estáo submetidos, às questôes políticas que explodem e exploram o cotidiano, preocupações com a falta de saúde, qualificação e acesso ao mercado de trabalho. Já a faixa de 25 a 29 anos, de forma geral, apresenta uma análise em que a configuração da realidade parece emoldurada pelas repressóes e impossibilidades. Uma juventude que reproduz um discurso antigo, acompanhado de uma aparente aceitação das "coisas como são", embora haja exceçóes que parecem escapar um pouco à regra da adaptaçáo imediata, porque questiona a realidade.

$\mathrm{Na}$ carta municipal da juventude, foram indicados dois caminhos: a urbanização e a revitalização de espaços públicos no centro e nas periferias da cidade, porque entendem que isso amplia interfere na banalização da violência.

Outro tema de diálogo nos ciclos se referiu às questôes de gênero. Esse tema surgiu entre os participantes entre 18 e 29 anos e se mostrou uma preocupação frequente, a ponto de se tornar a prioridade 3 da carta municipal: "respeito e igualdade entre orientaçóes sexuais, gêneros e suas identidades", com desenvolvimento de açôes específicas com ênfase na diversidade, garantindo espaço para inclusão de temas sobre questóes étnicas, raciais, de deficiência, de orientação sexual, de identidade e gênero e de violências doméstica e sexual praticada contra a mulher. (CARTA MUNICIPAL DA JUVENTUDE, 2013)

Vale salientar que a ênfase ao gênero é uma noção que permite entender melhor as representaçóes sociais de masculino e feminino na prática social. Assim, tratar da violência na questão de gênero é trazer à tona todas as questóes relacionadas aos seres humanos, sobretudo os que sofrem com o preconceito instalado nas relaçóes. Os presentes nos diálogos analisaram as relaçôes de poder que auxiliam na violência e vitimização das minorias, uma violência que normalmente acontece do pai para com o filho, do esposo para com a esposa, do chefe para com o empregado, daqueles que encontram na fragilidade do outro a construção do seu poder de destruição. Os jovens compreendem que a escola poderia contribuir desde muito cedo para a construçáo de uma geraçáo mais saudável e atenta aos direitos do outro, considerando que essa escola é formadora de personalidades, mas ela precisa ser coerente entre o discurso e as práticas cotidianas: o 
jovem mogiano indica a inclusão nos conteúdos curriculares da educação de informaçóes sobre discriminação na sociedade e sobre o direito de todos os grupos e indivíduos a tratamento igualitário perante a Lei; e inclusão, nos conteúdos curriculares, de temas relacionados à sexualidade, respeitando a diversidade de valores e crenças。 (CARTA MUNICIPAL DA JUVENTUDE, 2013)

Indicam que a escola precisa ampliar o conhecimento dos professores, bem como dos demais atores educacionais para o cumprimento do seu papel, com atenção às situaçóes do cotidiano, ouvindo as demandas dos alunos, observando e acolhendo as inquietaçóes.

Até aqui, discutimos as prioridades da juventude mogiana no que se refere a duas dimensôes: a de expectativa formadora que gera oportunidades de trabalho e sucesso, e sua antagonista, a ausência de formaçáo que gera a violência contra os mesmos.

Ouvir os jovens permite pensar que, na sociedade administrada, todos são convocados a participar da lógica da adaptação e da dominação social, em que se mascara a falta de oportunidade para todos. Aos jovens são atribuídas responsabilidades pelas escolhas, deles é cobrada a administração das emoçóes, a superação das crises pessoais, sociais e do trabalho, a eles são atribuídas as consequências dos seus atos e a culpa pela violência cotidiana na sociedade. Nessa perspectiva, existe uma exclusão do sujeito, mas quando ele é resgatado é para ser subjugado e dominado nas suas relaçôes.

Os ciclos de diálogo oportunizaram um caminho, que de certa forma libertou momentaneamente os jovens e possibilitou um olhar sobre si mesmos e suas relaçóes, gerando uma fagulha de libertação.

\section{A cidade sob o olhar da juventude: cenários possíveis}

$\mathrm{Na}$ carta municipal da juventude fica claro o interesse dos jovens em participar do processo de construção e desenvolvimento da cidade. Percebem-se enquanto atores indispensáveis e abrem espaço para a construção possível:

Acreditamos que somos atores em um processo de transformação no nosso município [...] consideramos que a construção 
das cartas distritais traduz o pensamento local e está carregado de intençôes, desejos, anseios da população jovem [...] este documento tem a intenção de expressar o pensamento da juventude e é síntese da participação. (CARTA MUNICIPAL DA JUVENTUDE, 2013)

A vida em uma cidade média, como é o caso de Mogi das Cruzes, é uma experiência importante e intensa de socializaçáo e exige uma mobilização para o entendimento do espaço e da convivência com o outro, em suas relações. É preciso entender como se dão essas relaçôes entre estranhos que compartilham algumas experiências e as possibilidades que temos de olhar para os territórios em que elas se dão.

Os jovens de Mogi das Cruzes são orgulhosos da cidade e se sentem pertencentes aos seus territórios como bairros, encontram sentido em buscar soluçôes para um entendimento entre as dificuldades e o convívio social, nem sempre harmonioso, e estão dispostos a lutar pelo desenvolvimento da cidade.

Para Bauman (2010b), há um preço a pagar pelo privilégio de viver em comunidade e este é pequeno e até invisível, mas existe até quando viver em comunidade for um sonho. Para ele, não ter uma comunidade referência significa não ter proteção; alcançar a comunidade e estabelecer uma relação de orgulho e pertencimento poderá significar a perda da liberdade. A segurança e a liberdade são dois valores muito presentes nos diálogos, pois os jovens entendem que o compromisso com o bairro, com o distrito ou com a cidade gera uma responsabilidade que lhes possibilita superar a crítica vazia e exige uma participação efetiva e presente.

$\mathrm{Na}$ Vila Nova União, os jovens não tiveram interesse em discutir o bairro da forma apaixonada como em tantos outros. Essa regiáo vive um problema de pertencimento e, segundo os próprios jovens, isso ocorre porque o processo de legalizaçáo em grande parte dos lotes que ocupam ainda não foi concluído. Esses jovens não se sentem protegidos e não conseguem estabelecer essa relação de orgulho que Bauman compreende como essencial para a vida em comunidade.

A carta distrital de César de Souza diz ser Mogi das Cruzes "uma cidade com grande potencial para articular políticas públicas e garantir a excelência do processo de garantia de direitos". Na carta de Braz Cubas, 
os jovens afirmam: "somos conscientes que temos muitas possibilidades e as pesquisas nos mostram que tantas vezes somos negligentes com nosso compromisso, mas também sabemos que somos capazes de muito mais, se nos forem dadas oportunidades"; na carta de Biritiba Ussu, deixam claro como se consideram: "o maior ativo do nosso distrito são as pessoas [...] temos desejo de participar da vida pública do nosso município”; em Jundiapeba expressam o desejo e o compromisso com o objetivo do projeto: "explicitamos nosso interesse em participar do desenvolvimento do nosso distrito e contribuir com a nossa força jovem nos rumos que essa cidade irá trilhar nas próximas décadas."

O sonho construído pela juventude mogiana passa pela possibilidade de viver em comunidade de forma plena, que os que foram embora voltem, e os que ali estão encontrem sentido para permanecer. Os bairros periféricos sonham em superar o estigma de violência e descompromisso com a cidade, os bairros centrais desejam abandonar a marca da degradação e do sentido único comercial e se tornar foco de políticas de revitalização, e os bairros rurais anseiam em se sentir pertencentes ao universo da cidade, sem perder as características que lhes são peculiares, conservando sua vocação produtiva e oferecendo oportunidade para seus munícipes.

A cidade, na visão dos jovens, além de possuir um dinamismo populacional e econômico, há que destacar seu papel enquanto polo representativo do Alto Tietê, responsável por proporcionar certo equilíbrio interurbano nas características regionais. $\mathrm{O}$ contexto de uma cidade média do estado de São Paulo e uma população crescente, exige políticas públicas eficientes que possam garantir uma vida digna a seus moradores, oportunizando melhoria nas condiçóes de moradia, educaçáo, oportunidade de emprego, entre outras.

Num momento em que manifestaçóes nacionais aconteciam pelo país, é interessante observar como esses jovens percebiam a questão da mobilidade urbana:

As políticas de mobilidade devem permitir aos jovens irem e virem com liberdade, com priorização dos transportes coletivos e náo motorizados. Devem promover a acessibilidade e a mobilidade nos espaços urbanos, também a partir da expansão e manutenção dos transportes públicos de qualidade, a meia 
passagem, a redução das tarifas, a ampliação dos horários e a construção ou ampliação de ciclovias. (CARTA DISTRITAL DA JUVENTUDE, CENTRO, 2013)

Foi possível perceber que os jovens valorizam os espaços formativos, ainda que nem sempre encontrem as palavras certas para dizer e os espaços para praticar. Em quase todos os ciclos de diálogo, o papel formativo das instituiçôes como família, escola, mídia e instituiçôes religiosas, assim como as instituiçóes não formais aparece como mote para uma discussão que nos parece muito profunda e impossível de ser aqui esgotada. Para esses jovens, estamos diante de um grande desafio: Como uma cidade como a nossa pode aproveitar as oportunidades para se tornar uma cidade educadora?

Os jovens sonham em ter acesso à cultura farta e de boa qualidade, a espaços e projetos esportivos acessíveis em níveis básicos e profissionalizantes, sonham que a educação em todos os seus níveis possibilite a sua formação integral, ao mesmo tempo que revelam profundo descontentamento com os rumos que essas instâncias formativas tomam. A cidade, na visão deles, parece não haver encontrado ainda a fórmula para garantir a unificação das açôes, os projetos de formação para a juventude estáo presentes nas diversas secretarias, porém sem uma conexão que garanta a sua eficiência:

Implementação de políticas municipais de cultura, de esporte e lazer, que criem novos espaços de produção, fruição e interação entre os jovens, valorizando e integrando os espaços já existentes - propostas nas cartas distritais. [...] Faz-se necessária ainda a garantia de equipamentos públicos que articulem programas de diferentes pastas dirigidos a jovens, as possibilidades de acessibilidade para jovens com deficiências, bem como a democratização da gestão destes para que se adequem as práticas e realidades de cada local. (CARTA MUNICIPAL DA JUVENTUDE, 2013)

A prioridade na construção de uma cidade sustentável que seja capaz de uma visão global para os problemas e para as soluçóes, que possibilite a participação dos seus moradores de forma mais efetiva: 
Precisamos construir uma cidade inclusiva, sustentável, saudável e democrática que proporcione uma boa qualidade de vida à juventude e ao conjunto da populaçáo tendo em conta a preocupação com as gerações futuras. Sonhamos com uma cidade que garanta a participaçáo da sociedade em todos os aspectos relativos à vida pública. (CARTA DISTRITAL DA JUVENTUDE, CENTRO, 2013)

O que se pode perceber é uma cidade que está em busca de abrir espaços de representação, e os jovens, que pareciam dispersos, inertes, alienados, ao terem oportunidade para falar e ser ouvida, num processo em que viram sentido, começaram a se abrir para essa possibilidade. Isso ficou claro na carta municipal da juventude quando a prioridade foi: "incentivar a participação do jovem para o caráter representativo, mas, sobretudo, para saber se organizar de forma cidadã e responsável”, e ainda:

Promover espaços de participação efetiva por parte dos jovens, buscando a consolidação da democracia participativa e fortalecendo o município. Incentivar mediante mecanismos legais o fomento de grupos de representação juvenil, para contribuir com a formação estruturada e crítica do pensamento. (CARTA MUNICIPAL DA JUVENTUDE, 2013)

Por fim, a carta municipal, resultado de uma construção coletiva, indica ao poder público que: Institucionalize uma Política Municipal de Juventude, no Executivo e no Legislativo, incluindo a constituição de comissóes de juventude na câmara municipal, criação do conselho de juventude em consonância com a Lei No 12.852/2013, aprovação da inclusão da juventude na lei orgânica municipal, a elaboração e aprovação de um Plano Municipal de Juventude, a criação e implementação de um órgão especializado de gestão e articulação das políticas específicas e estruturais, com orçamento próprio (Orçamento Juventude) e garantia de inserção intersetorial e transversal nas decisóes do governo. Crie um observatório para promoção de estudos e pesquisas e a obtenção de estatísticas e informaçóes relevantes, a fim de subsidiar as açóes relacionadas à juventude e permitir a avaliação periódica dos impactos das políticas públicas. Constitua uma 
ouvidoria jovem com espaço para ouvir os jovens de forma também presencial, observando as necessárias representaçôes de acordo com o território se suas especificidades.

\section{Consideraçóes finais}

Gohn (2006, s/p) defende que:

Não é mais possível permanecer no conformismo diante de espaços dominados por antigos métodos clientelistas, pela ordem tradicional. É preciso criatividade e ousadia porque as novidades só ganham força quando passam a ter hegemonia em certos coletivos organizados mais amplos. Por isso, é preciso voltar os olhos para a organização da sociedade civil, para os processos de educação não-formal que nela se desenvolvem [...] Precisamos de uma nova educação que forme o cidadão para atuar nos dias de hoje, e transforme culturas políticas arcaicas, arraigadas, em culturas políticas transformadoras e emancipatórias. Isso não se faz apenas em aulas e cursos de formação tradicionais, formulados no gabinete de algum burocrata, ou de seminários de capacitação -usualmente só técnica; isto se faz sim a partir da prática da gestáo compartilhada [...] numa determinada comunidade territorial. [...] Não basta um programa, um plano, ou mais um conselho. É preciso reconhecer a existência e a importância da educação não-formal no processo de construção de uma sociedade sem injustiças, democrática. É preciso sistematizar dados, gerar e extrair saberes, e produzir conhecimentos no campo da Pedagogia Social.

Descrevemos aqui uma experiência nessa direção, e realizamos uma pequena análise de alguns elementos que emergem dela.

$\mathrm{O}$ trato com a juventude no mundo se configura como um desafio e no cenário brasileiro náo é diferente. O panorama dos movimentos sociais, das manifestaçôes e da necessidade dos jovens de participar da gestão pública é uma realidade e é urgente que se encontrem métodos e estratégias 
para garantir uma aproximação produtiva que vise resultados satisfatórios para a democracia brasileira.

O projeto aqui descrito resultou em uma cartografia do olhar da juventude sobre a cidade e a criação de espaços de diálogo permanente, de forma presencial e utilizando a internet, sobretudo as redes sociais.

Essa iniciativa do poder público se apresentou, a partir dos resultados alcançados em Mogi das Cruzes, como uma iniciativa positiva de aproximação entre o cidadão e a gestão pública, podendo ser replicada, considerando os resultados alcançados com a mobilização de 4.072 jovens nos ciclos de diálogo e a construção de um plano de ações que gerou compromissos entre as partes, apesar dos limites existentes.

A estratégia de aproximação com os jovens dos distritos por meio dos Ciclos de Diálogo proporcionou a abertura de um canal de comunicação em que os jovens cidadãos podem sentir-se ouvidos e fazer parte de um processo genuinamente participativo.

A iniciativa demonstrou grande potencial de mobilização, considerando o grande número de lideranças que compóem o mosaico juvenil presente na cidade. O leque de organizaçóes e grupos dispostos a desenvolver trabalhos com esse público e o conhecimento que os próprios jovens podem ter permitem um avanço social prático e concreto, visando a eficiência na implementação de políticas, programas e projetos.

As indicaçóes da juventude, por meio da Carta da Juventude Mogiana foram recebidas pelo entáo prefeito e os encaminhamentos formais foram realizados, inclusive reunióes nas quais a juventude pôde dialogar e criar um plano de metas para a constituição da política municipal de juventude para o município.

A ação mais importante, naquele momento, era a instituição do Conselho Municipal de Juventude, por meio do Projeto de Lei em trâmite na Câmara Municipal da cidade (mas o Conselho só foi instituído em 2015). Houve o início do curso de Fundamentos das Políticas de Juventude para os membros indicados ao Conselho de Juventude e um plano de trabalho para início imediato de um programa de reaproximação dos grupos que já haviam sido alcançados pela pesquisa.

A instituiçáo do Conselho e da política de juventude passou pelos desafios ligados ao que se convencionou chamar, no Brasil, de 'velha política', mas seguiu avançando, na prática, inclusive pela mudança nas lide- 
ranças mediadoras do processo junto ao poder público e pela implantação do primeiro Conselho Municipal de Juventude.

A experiência concreta, a pesquisa e a divulgação de seus resultados querem servir como alento às novas geraçóes e a muitas outras juventudes do Brasil, tanto quanto à perspectiva de novas experiências de construção coletiva de políticas públicas, sobretudo com jovens. Eles são especialmente abertos a uma efetiva pedagogia social.

É possível ser ouvido pelo poder público, é possível construir coletivamente uma política pública e é possível obter uma efetiva participação dos jovens, ainda que haja muito a mudar em relação à velha política.

\section{Referências}

CALIMAN, G. Pedagogía social. In: PRELLEZO, J.M. (Org). Diccionario de Ciencias de la Educación. Madrid: Editorial CCS, 2009. p. 889-890.

ADORNO, T. W. Capitalismo tardio ou sociedade industrial. São Paulo: Ática, 1986. (Coleçâo Grandes Cientistas Sociais). . Educação e emancipação. São Paulo: Paz e Terra, 1995.

2005. . Teoria da semicultura. EducaçãodSociedade, ano IV, n. 191, p. 1-19, ago.

ADORNO, T. W.; HORKHEIMER, M. Dialética do esclarecimento. Rio de Janeiro: Jorge Zahar, 1985.

BAUMAN, Z. Confiança e medo na cidade. Rio de Janeiro: Editora Zahar, 2009. . Capitalismo parasitário. Rio de Janeiro: Zahar, 2010a.

2010b. Comunidade: a busca de segurança no mundo atual. Rio de Janeiro: Zahar, _-____. Sobre educação e juventude. Rio de Janeiro: Editora Zahar, 2013 a.

. Danos Colaterais. Rio de Janeiro: Zahar, 2013b.

BRASIL. Constituição (1988). Constituição da República Federativa do Brasil. Brasília, DF: Senado Federal, 1988.

. Câmara dos Deputados. Projeto de Lei no 4.530, de 2004. Aprova o Plano Nacional de Juventude e dá outras providências. Brasília, DF: Câmara dos Deputados, 2004. 
. Secretaria Nacional de Juventude. As 22 prioridades da $1^{a}$ Conferência. Brasília, DF: SNJ, 2008a.

. Secretaria Nacional de Juventude. Guia das políticas públicas de juventude. Brasília, DF: SNJ, 2010a.

Secretaria Nacional de Juventude. Marcos da politica nacional de juventude. Disponível em: http://www.juventude.gov.br/marcos/view. Acesso em: 24 jul. 2012d.

. Secretaria Nacional de Juventude. Mapa da violência 2013. Brasília, DF:. Disponível em: http://www.mapadaviolencia.org.br. Acesso em: 25 dez. 2013.

Lei no 12.852, de 05 de agosto de 2013. Institui o Estatuto da Juventude. Diário Oficial da União, Brasília, DF, 2013a.

COOPERRIDER, D. L. Captando o que mais importa na prática do appreciative inquiry. Cleveland, OH: Western Reserve University, 1998.

COSTA, M. O. Trabalho decente segundo estudos da Organização Internacional do Trabalho. Jus navigandi, out. 2010. Disponível em: http://jus.com.br/revista/ texto/17550/trabalho-decente-segundo-estudos-da-organizacao-internacional-dotrabalho. Acesso em: 17 set. 2012.

COSTANZI, R. N. Trabalho decente e juventude no Brasil. Brasília, DF: Organização Internacional do Trabalho, 2009.

GOHN, M. G. Educação não-formal na pedagogia social. In: CONGRESSO INTERNACIONAL DE PEDAGOGIA SOCIAL, 1., 2006, São Paulo. Anais... São Paulo: Faculdade de Educação, Universidade de São Paulo, 2006. Disponível em: http://www.proceedings.scielo.br/scielo.php?script=sci_arttext\&pid=MSC0000000092 006000100034\&lng=en\&nrm=abn. Acesso em: 10 ago. 2012.

HORKHEIMER, M.; ADORNO, T. W. Temas básicos de sociologia: Estudos de comunidade. São Paulo: Editora Cultrix, 1956.

MOGI DAS CRUZES. História. Disponível em: http://www.mogidascruzes.sp.gov.br/ turismo/historia.php. Acesso em: 29 nov. 2013.

ORGANIZAÇÃO DAS NAÇÕES UNIDAS (ONU). Objetivos de Desenvolvimento do Milênio (ODM). Disponível em: http://www.odmbrasil.gov.br/. Acesso em: 12 nov. 2013.

Recebido em 6 mar. 20I9 / Aprovado em II jun. 2019

Para referenciar este texto:

ROGGERO, R.; SIQUEIRA, L. O. A construção de uma política de juventude com os jovens: possibilidades e limites de uma experiência concreta. EccoS - Revista Científica, São Paulo, n. 49, p. I-29, eI3191, abr./jun. 2019. Disponível em: https:// doi.org/I0.5585/EccoS.n49.I3I9I. 